\title{
EVOCAR ATMÓSFERAS. \\ ARQUITECTURA SUIZA CONTEMPORÁNEA Y SU EXPRESIÓN VISUAL DEL PROYECTO
}

\author{
Angélica Fernández-Morales
}

Evoking atmospheres. Swiss contemporary architecture and its design's visual expression

Boletín Académico. Revista de investigación y arquitectura contemporánea

Escuela Técnica Superior de Arquitectura. Universidade da Coruña

elSSN 2173-6723

unw.boletinacademico.com

Número 4 (2014)

Páginas 53-62

Fecha de recepción 30.10.2013

Fecha de aceptación 10.01.2014

https://doi.org/10.17979/bac.2014.4.0.1009

\section{Resumen}

El artículo se centra en la escena suiza contemporánea, y presenta diversos ejemplos de cómo es expresada visualmente la esencia atmosférica en el proyecto arquitectónico. El texto se estructura relacionando la atmósfera con varios aspectos: el lugar, la escala humana, la luz y el aire. Entre los arquitectos tratados se incluyen Herzog \& de Meuron, Peter Zumthor, Christian Kerez, Gigon \& Guyer, Miroslav Šik y Philippe Rahm. Se distinguen dos modos de expresión: los de carácter abstracto y diagramático y los que buscan la previsualización realística. En ambos casos, lo importante es la capacidad de evocar la vivencia de la arquitectura proyectada.

\begin{abstract}
The article focuses on contemporary Swiss scene, and presents several examples of how atmospheric essence is visually expressed in architectural design. The text structure considers the relationship between atmosphere and other variables: the place, the human scale, light and air. Among the architects covered are Herzog \& de Meuron, Peter Zumthor, Christian Kerez, Gigon \& Guyer, Miroslav Šik and Philippe Rahm. Two approaches can be identified: an abstract and diagrammatic, and a realistic. What matters, in both cases, is the ability to evoke the experience of the designed architecture.
\end{abstract}

\section{Palabras clave}

Suiza, atmósfera, Herzog \& de Meuron, Kerez, Zumthor

\section{Keywords}

Switzerland, atmosphere, Herzog \& de Meuron, Kerez, Zumthor 


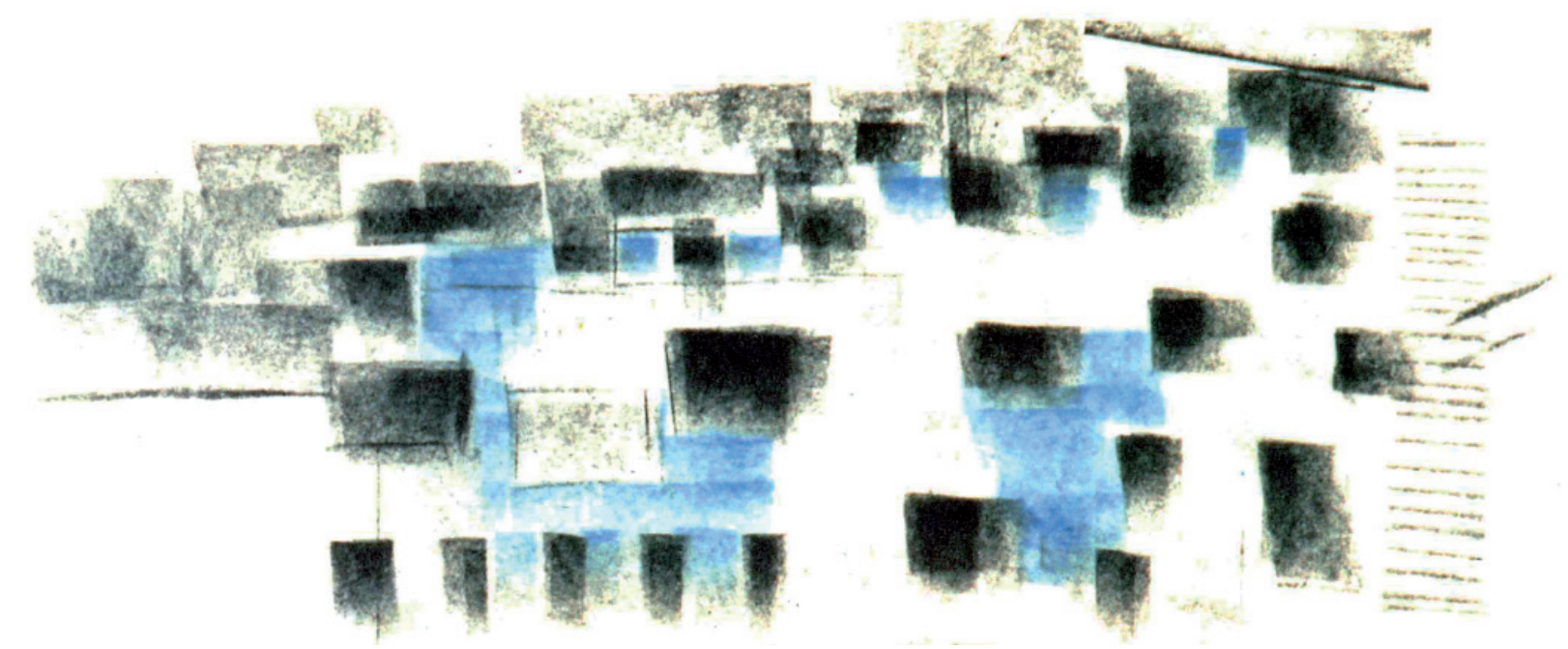

01 Peter Zumthor, Boceto para las termas de Vals (Graubünden, Suiza), 1986/96.

La idea de atmósfera tiene un peso importante en la arquitectura suiza de las últimas décadas, una arquitectura caracterizada por su simplicidad formal, su integración en el entorno y su hábil tratamiento de los materiales para desplegar todo su potencial sensorial. Zumthor es probablemente quien más énfasis ha puesto en la creación de determinadas atmósferas, y en relatar la influencia que tienen las que él ha experimentado, a lo largo de su vida, en la concepción de sus obras ${ }^{1}$. Herzog $\&$ de Meuron también inciden en la importancia de lo atmosférico en la arquitectura, especialmente en su componente no-visual: olores, temperatura, tacto... ${ }^{2}$

No es fácil plasmar gráficamente, en el proyecto arquitectónico, la atmósfera que tendrá un edificio o lugar, pues esta va, en buena parte, ligada a su materialidad física. Altés, analizando los dibujos de Peter Zumthor, opina que «los dibujos de arquitectura son siempre representaciones insuficientes, incapaces de reconstruir la esencia material y presente del objeto arquitectónico» ${ }^{3}$. No obstante, la necesidad de definir la esencia atmosférica está presente desde la fase de concepción del proyecto, ligada a los diversos parámetros del mismo: la ubicación del edificio —atmósfera y lugar-, su volumen y dimensiones - atmósfera y escala humana-, la definición de sus cerramientos —atmósfera y luz_, o la calidad ambiental de los espacios interiores —atmósfera y aire-.

\section{ATMÓSFERA Y LUGAR}

En el caso de Zumthor, las primeras ideas de proyecto se centran en la implantación del edificio en el lugar.
Su objetivo es conseguir que éste se integre como si siempre hubiese estado ahí, para lo cual es necesario analizar y comprender el emplazamiento a diferentes niveles. Tal y como el arquitecto expresa: «Cuando trato de identificar las intenciones estéticas que me motivan en el proceso de diseńo de edificios, me doy cuenta de que mis pensamientos giran en torno a temas como lugar, material, energía, presencia, recuerdo, memoria, imágenes, densidad, atmósfera, permanencia y concentración. Durante el proceso de trabajo, trato de dar a estos términos abstractos contenidos concretos relacionados con el encargo real $»^{4}$.

Los primeros bocetos muestran esa relación con el entorno, como se aprecia en el caso de las termas de Vals, en los que se propone una relación de continuidad material entre terreno y edificio (Fig. 01). Lo escueto y abstracto de esos bocetos no impide imaginarse el edificio integrado en la montańa, como sucede en el edificio construido (Fig. 02) Otro medio empleado por Zumthor son las maquetas de emplazamiento. Descartando las maquetas blancas y estrictamente volumétricas, Zumthor intenta plasmar la materialidad del lugar lo más fielmente posible, incorporando colores, texturas y vegetación, dando a los modelos una apariencia casi real (Fig. 03).

Es interesante abordar también los métodos de representación de la arquitectura análoga, movimiento que cobró fuerza en Suiza, en el contexto de la ETH de Zúrich, influido por las ideas del italiano Aldo Rossi, que fue docente allí durante dos ańos. Desde principios de los años noventa, la corriente ha sido impulsa- 


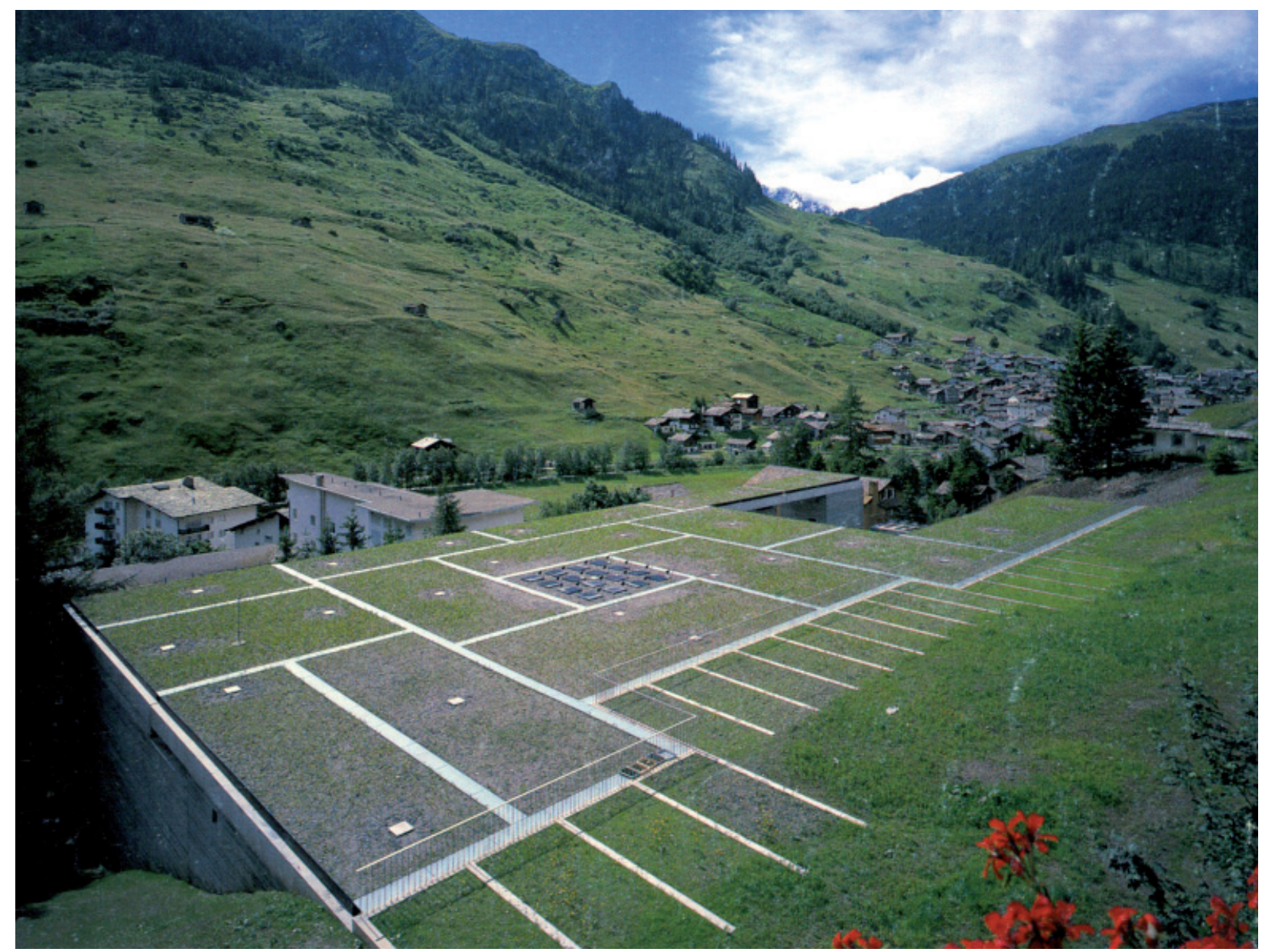

02 Peter Zumthor, Termas de Vals (Graubünden, Suiza), 1986/96.

03 Peter Zumthor, maquetas de diversos proyectos.

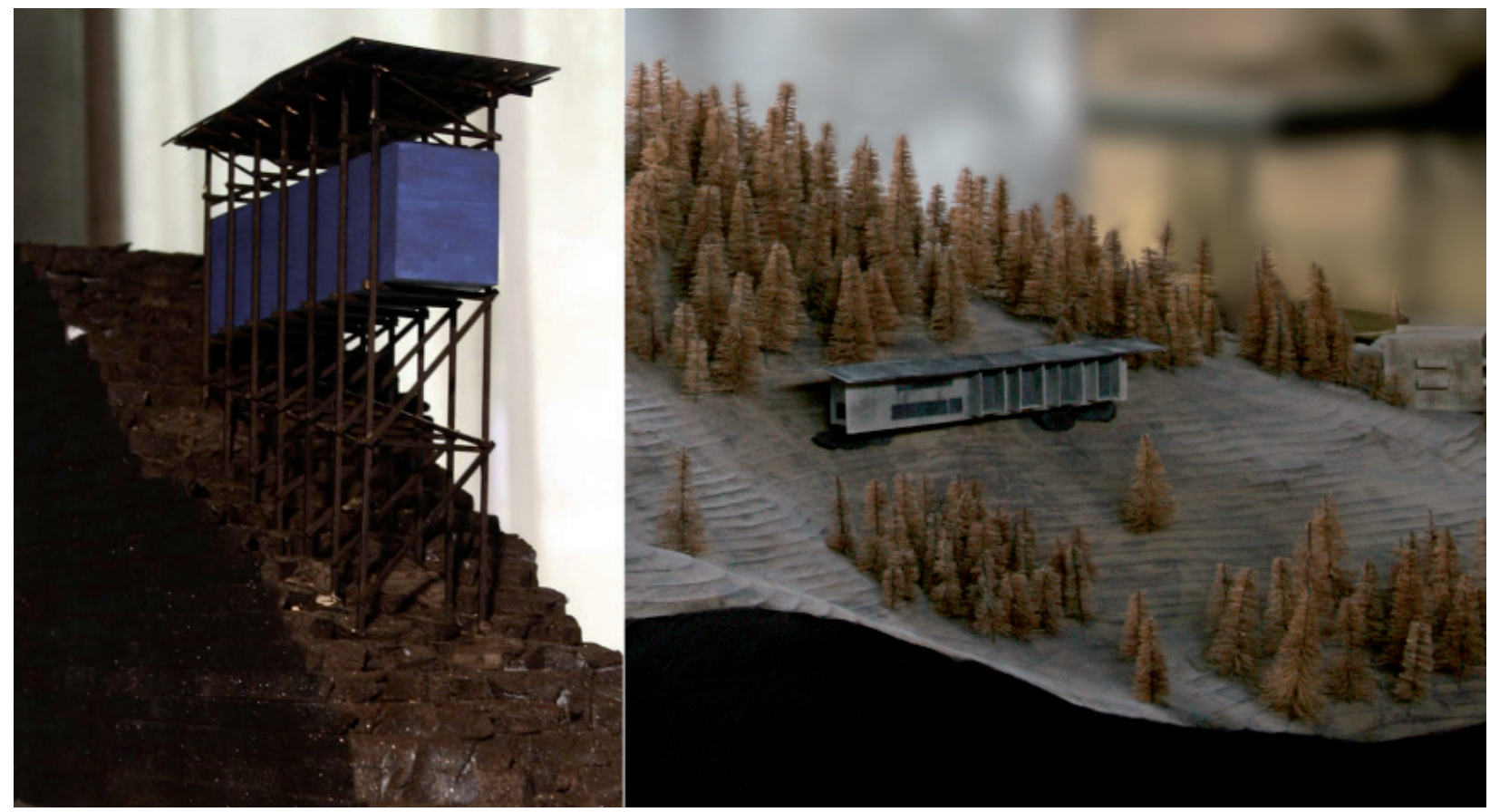



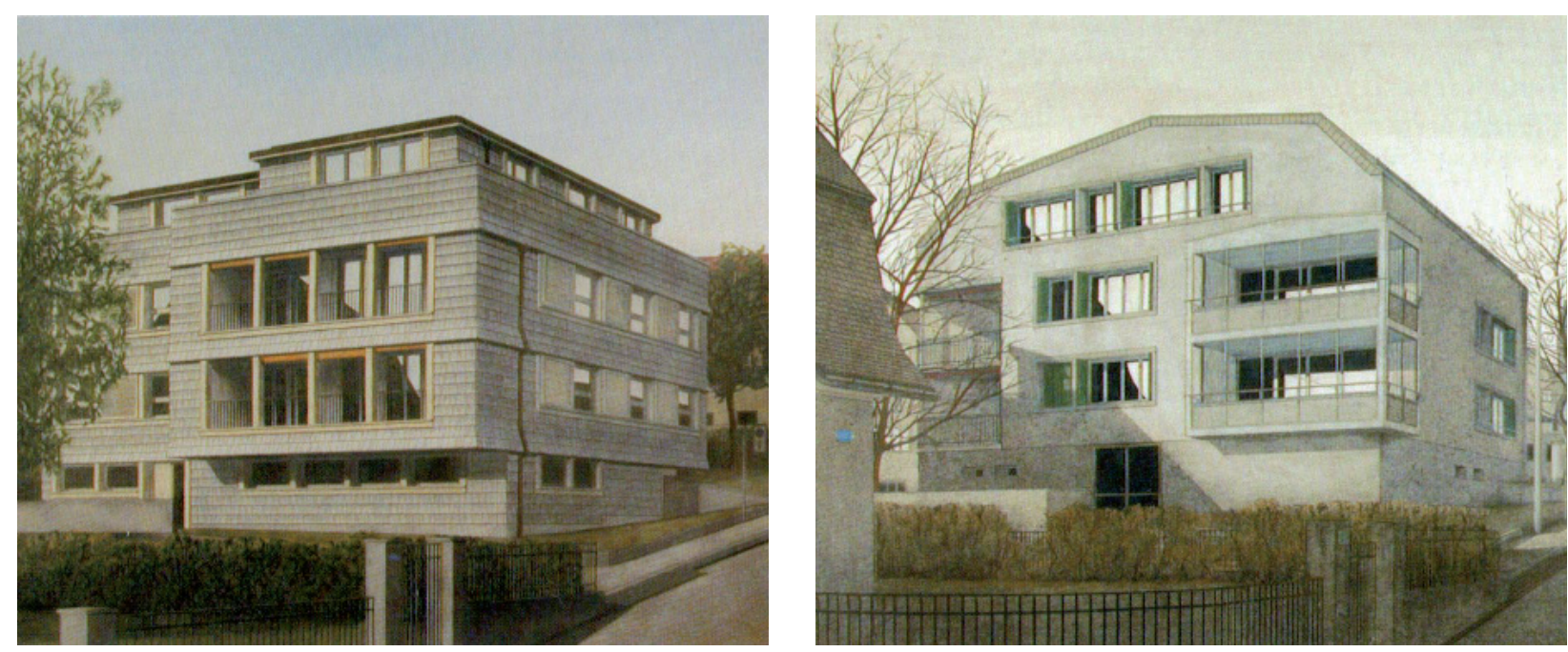

04 Trabajos de estudiantes de arquitectura, ETH Zúrich (profesor: Miroslav Šik).

da, sobre todo, por Miroslav Šik, y se caracteriza por prestar especial atención a la conservación de la atmósfera del lugar. Como describe Lucan, «la arquitectura análoga (...) [asume] la relativa inmutabilidad de la ciudad. El lugar, aunque no posea un valor aparente, nutre el proyecto; este se inspira en la arquitectura preexistente, incluso la a primera vista más vulgar o banal. El enfoque análogo se basa en el reconocimiento de la fuerza poética que subyace a las características comunes de un determinado lugar» ${ }^{5}$.

En las clases de Šik en la ETH, la arquitectura reconocible, de frrma, es sustituida por imágenes arquitectónicas cotidianas, extraídas del entorno inmediato. En lugar de proponer ejercicios con programas inusuales, Šik elige proyectos de orden doméstico y real, como la reforma de una vivienda unifamiliar de escala media en un barrio residencial. El objetivo final de la intervención es la unidad, la fusión con el lugar, introduciendo en él cambios leves, casi imperceptibles. Sik propone a los alumnos el dibujo detallado como medio de análisis del entorno y de resolución del proyecto: «Quiero que lo dibujen todo, incluso la suciedad en la carretera (...) así empiezan a pensar en cosas como la apariencia del asfalto calentado por el sol $\aleph^{6}$.

Originariamente eran grandes perspectivas a color, de un realismo casi fotográfico, hechas con lápices de cera (Fig. 04). En la actualidad, han sido sustituidas por la infografía digital fotorrealística, medio empleado también por Šik en su ejercicio profesional (Fig. 05-06). Pero las pautas son las mismas: el contexto es tratado con atención y detalle, y la propuesta arquitectónica se integra en él con naturalidad, sin que la iluminación, los colores — siempre suaves y poco saturados — o las texturas revelen ninguna discontinuidad. Podría hablarse de una pátina atmosférica que unifica arquitectura y lugar. Las imágenes muestran la capacidad del medio digital de una recreación fidedigna, muy próxima a la realidad construida.

\section{ATMÓSFERA Y ESCALA HUMANA}

Por otra parte, la atmósfera que un usuario experimenta en una determinada arquitectura es influida de forma decisiva por las dimensiones de la misma, y por la relación de escala que se establece entre ambos. Es algo que los artistas minimalistas sabían y tenían muy en cuenta a la hora de decidir las dimensiones de sus obras: la relación de escala que éstas establecían tanto con el espacio expositivo como con el observador, obligando a este último a tomar conciencia de su propia presencia física en relación a ellas. Esta conciencia de escala es compartida con los arquitectos, que en sus proyectos eligen, a menudo, formas de previsualización - tanto de los volúmenes exteriores como de los espacios interiores - desde un punto de vista, altura y ángulo visual similares a los del ojo humano. Se emplea, además, el recurso de añadir vida a los espacios representados - habitarlos, en definitiva, con personas y objetos - lo cual no solo facilita el dimensionado mental, sino también una mejor percepción del espacio.

En 1985, Jacques Herzog y Pierre de Meuron realizaron una instalación artística para la exposición 

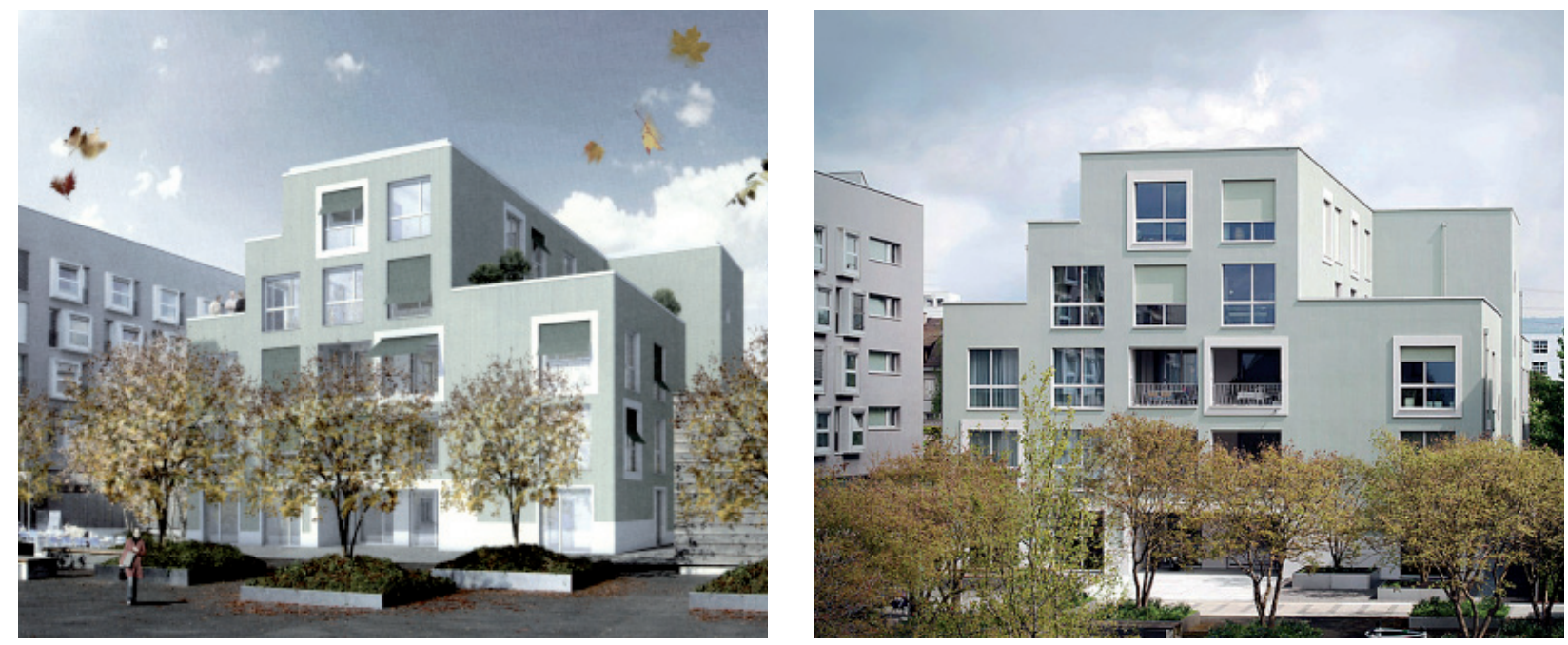

05-06 Miroslav Šik, Viviendas para la tercera edad (Zug, Suiza), 2007/12. Infografía del proyecto y fotografía del edificio terminado.

L'architecture est un jeu... magnifique (La arquitectura es un juego... magnífico) que tuvo lugar en el Centro Pompidou de París. Su trabajo, titulado Ein Haus aus Lego (Una casa de Lego) consistió en la construcción de una maqueta de una casa para ser filmada por dentro. La instalación la formaban la propia maqueta y dos fotogramas del video (Fig. 07).

Sobre el trabajo, los arquitectos escribieron: «La atmósfera en estas imágenes es creada por los elementos arquitectónicos, elegidos minuciosamente: una silla de madera pintada de blanco, un estante para la ropa, un rincón para hacer los deberes, un armario abierto adornado con corazones, y una cama con una manta a cuadros - miras a tu hermana, que ha llegado tarde a casa, quitarse la ropa - la luz y la sombra, la luna, la lámpara de mesa, la anodina lámpara de techo con pantalla de tela, cuya sombra se proyecta como una cara torcida sobre la pared $»^{7}$.

El texto no muestra la mirada de un arquitecto, sino la de un usuario común, y más que la propia arquitectura, lo relevante parecen ser los elementos ańadidos, que dotan de vida al lugar. Esas imágenes forman parte del trabajo arquitectónico de Herzog $\&$ de Meuron, sirviéndoles de inspiración. Para ellos, lo atmosférico de la arquitectura es tan importante como lo formal.

El recurso de construir maquetas para fotografiarlas fue empleado con posterioridad en sus proyectos, como el Schaulager en Basilea (1998/99), el Centro de Arte Walker en Minneapolis (1999-2002), el edificio Prada Aoyama en Tokio (2000/02), y otros.
Christian Kerez también ha trabajado intensamente con la previsualización a escala de sus proyectos. En 2006, en la presentación del proyecto para el concurso del Museo de Arte Moderno de Varsovia, se centró en plasmar y transmitir las cualidades atmosféricas del interior del edificio. Utilizó para ello el mismo recurso que Herzog \& de Meuron: el de filmar el interior de una maqueta, pero, en su caso, filmando un recorrido a modo de promenade architecturale virtual (Fig. 08). La maqueta, blanca y abstracta por fuera, contenía en su interior objetos y figuras humanas para facilitar la noción de escala. Hans Frei compara las maquetas de Kerez con cámaras caseras, objetos que ayudan a la construcción de imágenes y a la expresión de atmósferas: «Al principio, vemos la maqueta como un objeto, generalmente hecho con cartón-pluma. A medida que nos acercamos, sin embargo, la materialidad abstracta da paso a los verdaderos efectos de la luz que entra a través de las aberturas, así como a las perspectivas y puntos de vista que se abren entre los paneles; nos sumergimos en un mundo en miniatura, y tratamos de ajustar nuestro punto de vista a la orientación de los espacios. La maqueta es como una cámara, a través de la cual percibimos el entorno como una imagen ${ }^{8}$.

\section{ATMÓSFERA Y LUZ}

La luz es uno de los factores que más influye en la atmósfera de la arquitectura construida: permite la percepción de los volúmenes, los materiales y los colores, y condiciona el comportamiento de los usuarios de los edificios, permitiendo desarrollar sus actividades. En el caso de los espacios de exposición, esta importancia 

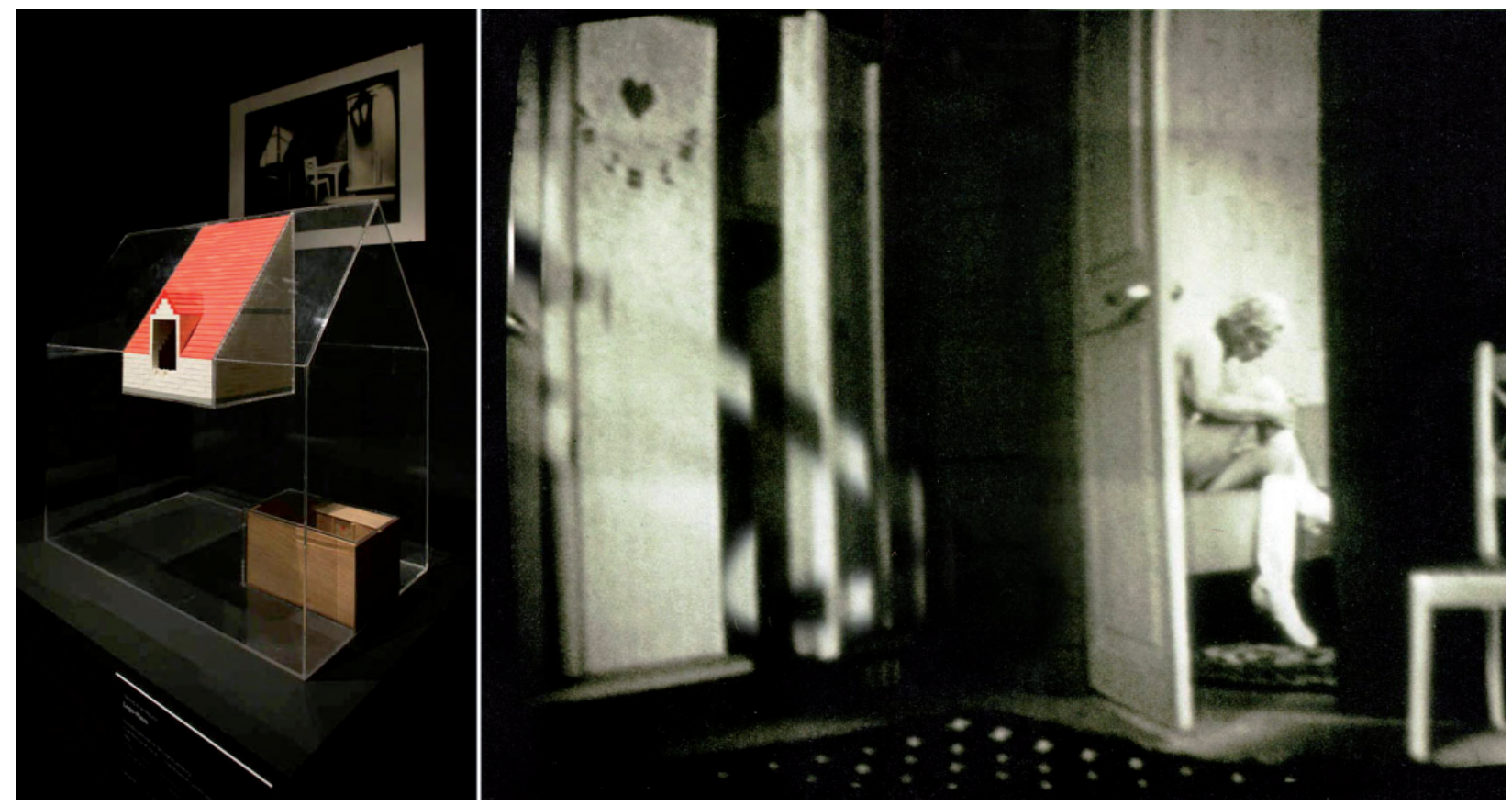

07 Herzog \& de Meuron, Ein Haus aus Lego, Centro Pompidou (París, Francia), 1985. Maqueta utilizada para la filmación, y fotograma.

$0 \mathbf{8}$ Christian Kerez, Museo de Arte Moderno (Varsovia, Polonia), 2006. Fotogramas del recorrido virtual por el interior de la maqueta de concurso.

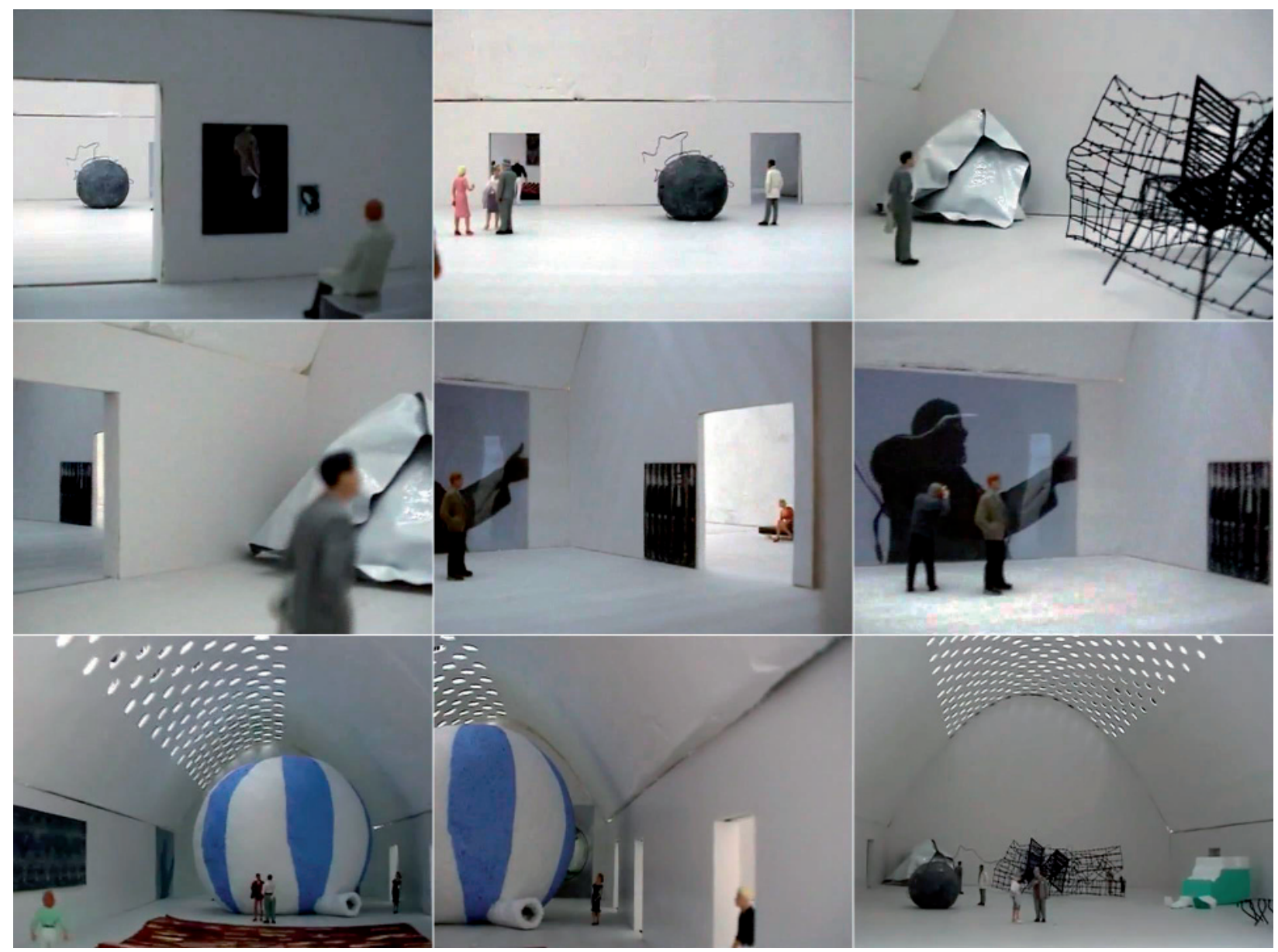



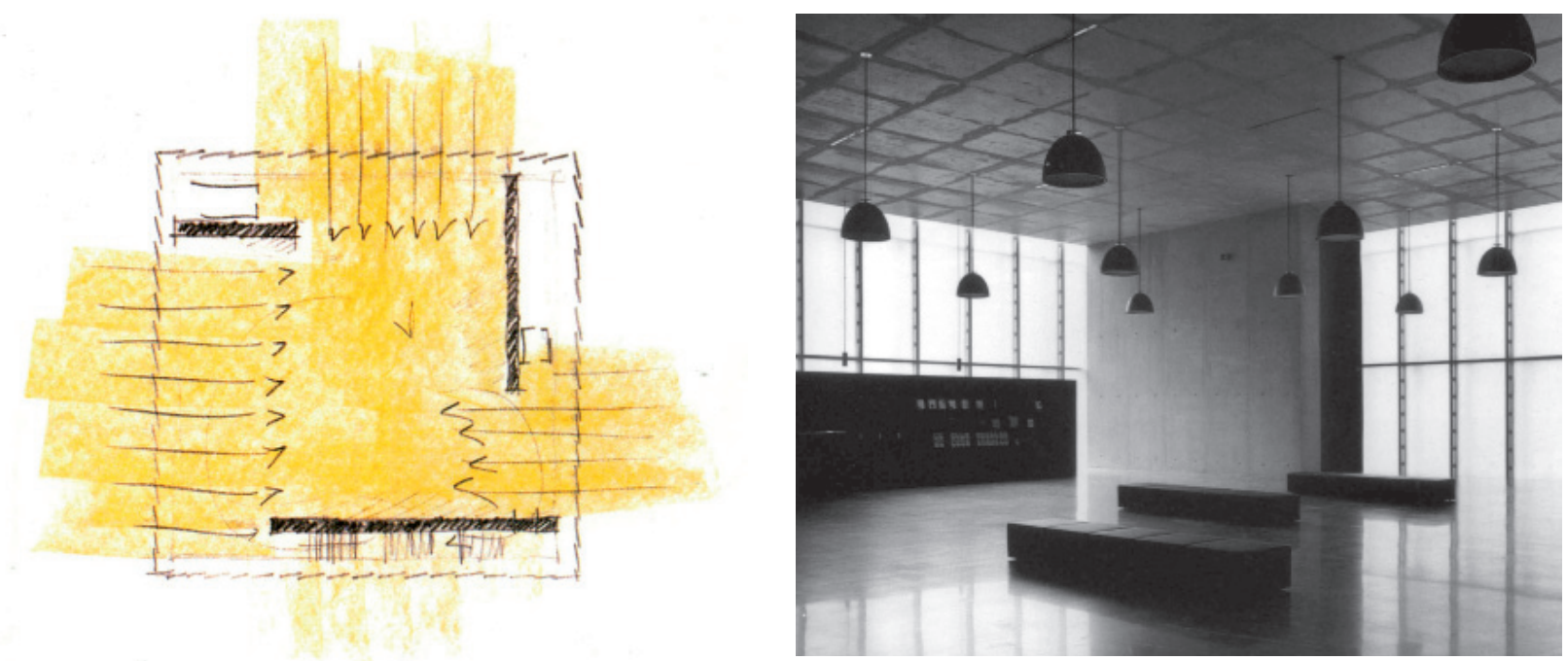

09-10 Peter Zumthor, Kunsthaus (Bregenz, Austria), 1990/97. Esquema de iluminación del vestíbulo y fotografía del vestibulo.

se acentúa, ya que la actividad principal es la de observar los objetos expuestos, y su correcta iluminación es primordial. Del mismo modo que en su boceto de las termas de Vals, Zumthor utiliza una representación esquemática en planta para explicar la iluminación del Kunsthaus Bregenz (Fig. 09). Ésta permite crearse una imagen mental del vestíbulo parecida al espacio real (Fig. 10), si bien deja parámetros por definir: el color de la luz, su intensidad, su grado de difusión (influido por las características del cerramiento), su reflexión en las superficies interiores, el efecto en los objetos expuestos... Opta, pues, por la aceptación de la parcialidad de la representación, y obliga al observador a aportar algo de su imaginación para completar la imagen.

Gigon \& Guyer, en cambio, aspiran a una previsualización realista y lo más fiel posible de la iluminación de los espacios interiores, y optan, por ello, por la fotografía de maquetas. A diferencia de Zumthor, ésta permite definir en buena medida los parámetros mencionados anteriormente, que influirán en la atmósfera del espacio museístico: material y transparencia de los cerramientos, tono de la luz, incidencia en las superficies... (Fig. 11)

Kerez adopta la misma postura que Gigon \& Guyer, como demuestran los fotogramas de la maqueta para el museo de Varsovia, en la que se reproducen las perforaciones de la cubierta, responsables de la iluminación natural de los espacios interiores. Pero el medio que mejor refleja la luz en ese proyecto es la infografía. En las infografías interiores, el carácter atmosférico del espacio y, en especial, la luz, cobran un papel protagonis- ta (Fig. 12). Las imágenes aspiran a un realismo fotográfico, ciñéndose a su misión de mostrar, de la forma más veraz posible, cómo será el espacio construido.

\section{ATMÓSFERA Y AIRE}

Por último se aborda el tema del aire y su papel en la creación de la atmósfera arquitectónica. Representar gráficamente el aire de un proyecto parece, a priori, tarea imposible, pero Philippe Rahm lo hace. Este arquitecto propone un nuevo modo de proyectar basado, precisamente, en las condiciones atmosféricas ${ }^{9}$, que da lugar, a su vez, a una representación gráfica diferente a la habitual, con nuevas posibilidades. Rahm clasifica su obra en las siguientes tipologías: radiación, conducción, convección, presión, evaporación y digestión, todos ellos conceptos asociados a la calidad atmosférica y a la actividad del cuerpo humano en ella. Trabajar con esos conceptos, de forma rigurosa, requiere la gestión de datos numéricos; por ello, el diagrama es el método principal de expresión visual de sus proyectos (Fig. 13).

\section{CONCLUSIONES}

Los ejemplos escogidos muestran la relación entre diferentes aspectos del proyecto y la creación de la atmósfera arquitectónica. Cuanto más vinculados estén dichos aspectos a la percepción visual, más fácil y precisa será su recreación gráfica: en el caso de la escala del edificio o su iluminación, su representación no ofrece dificultades — se ha visto su posible definición mediante plantas, maquetas, renders...-, mientras 


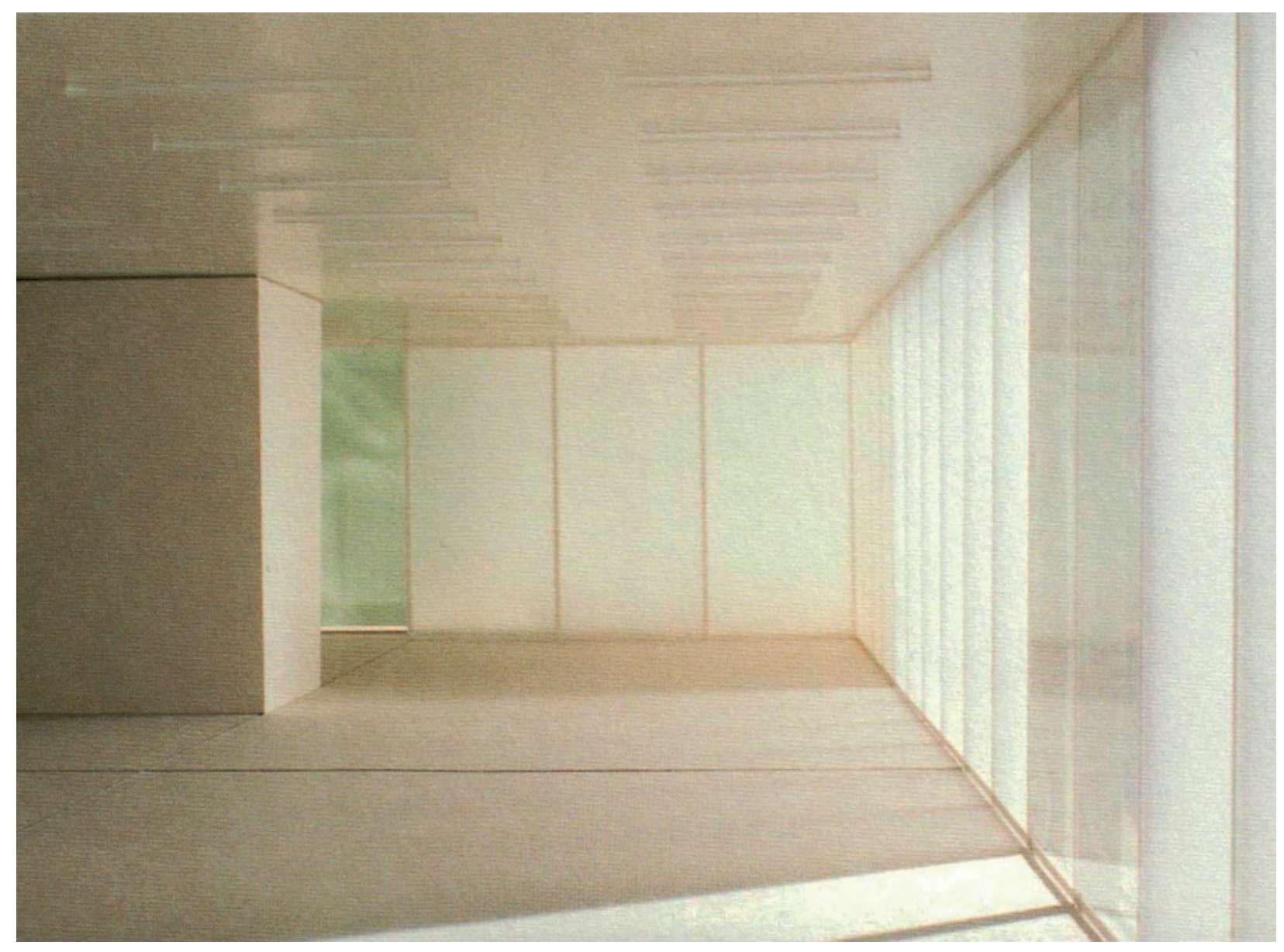

11 Gigon \& Guyer, Museo de arte Naduz, Liechtenstein), 1997. Fotografía de maqueta del concurso.

12 Christian Kerez, Museo de Arte Moderno (Varsovia, Polonia), 2006. Infografía del proyecto.

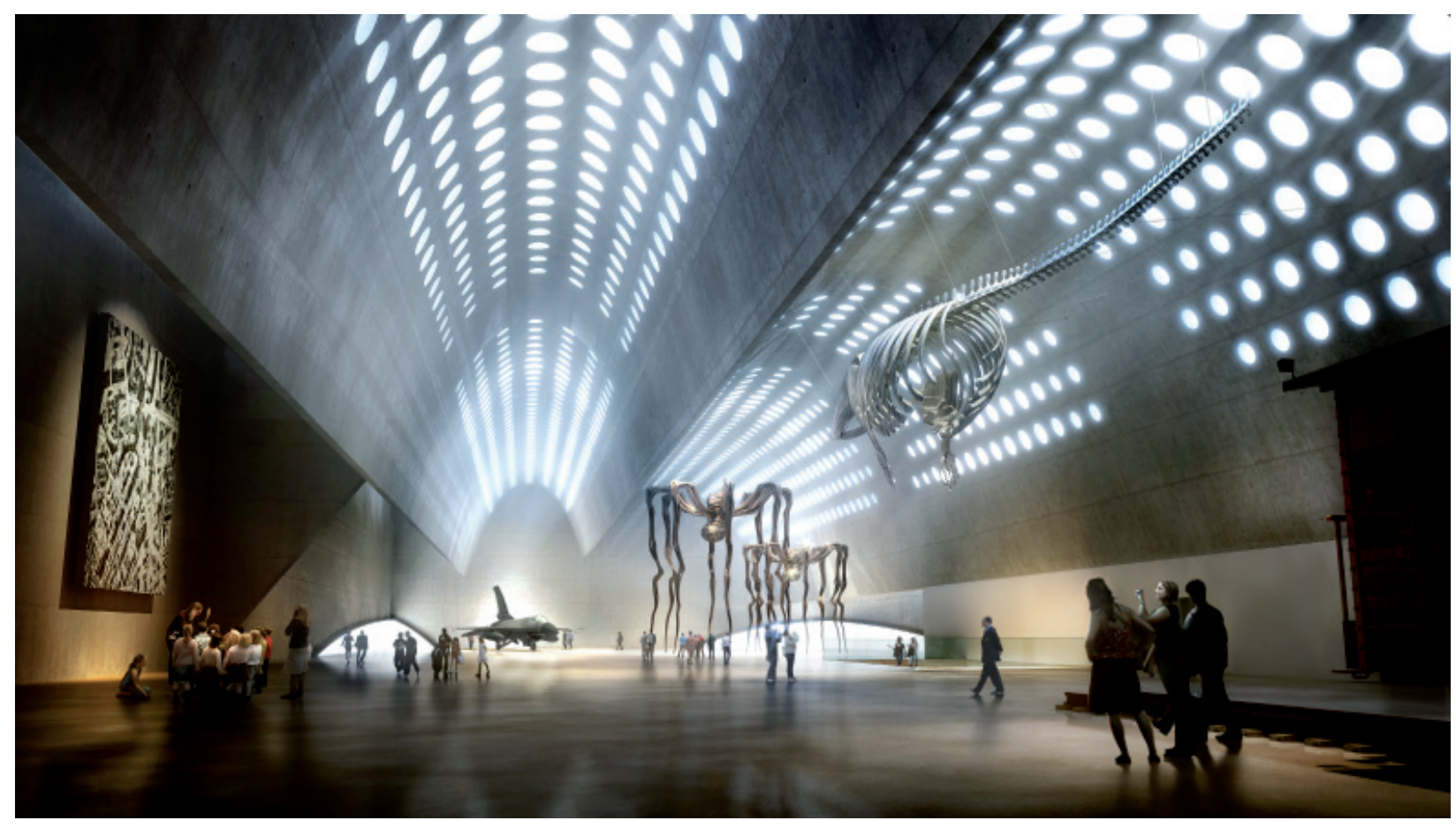




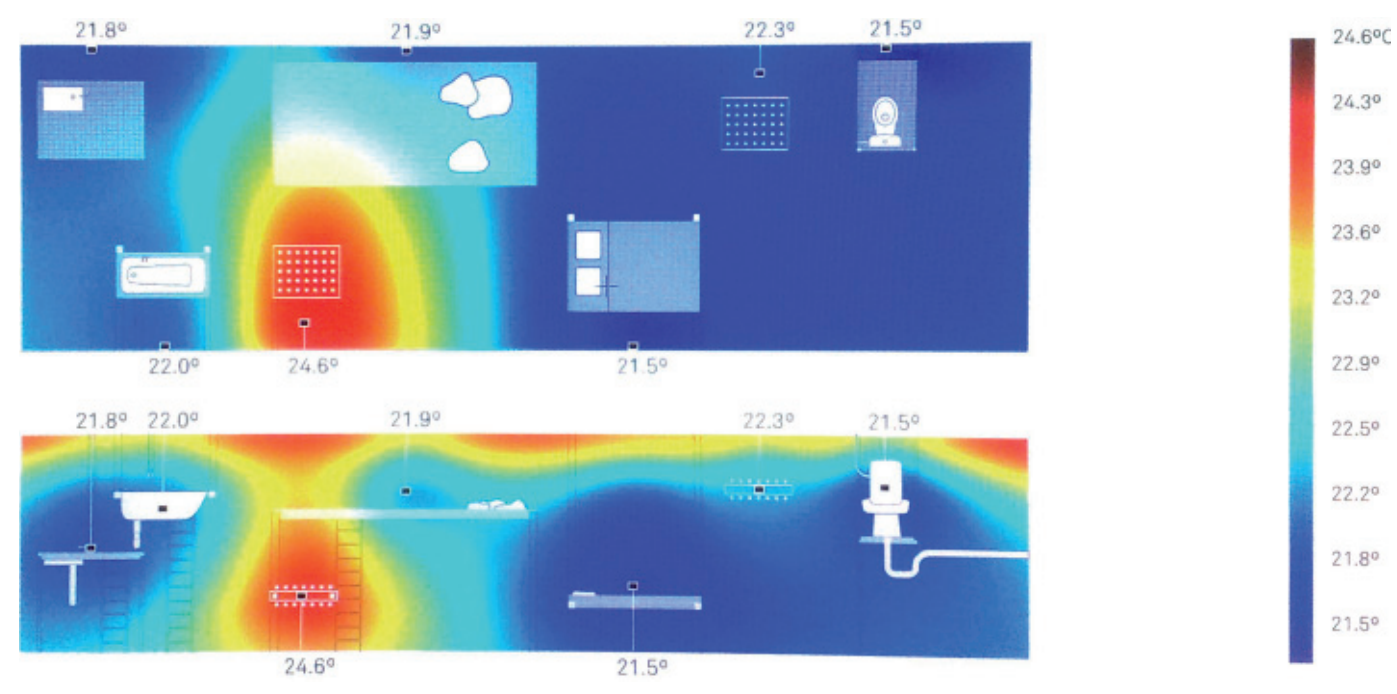

13 Philippe Rahm, Domestic Astronomy. Exposición Green Architecture for the Future (Humlebæek, Dinamarca), 2009.

que en el caso de las condiciones de temperatura, será necesario recurrir a métodos de representación menos obvios, como diagramas y códigos de color. Es cierto, sin embargo, que nuestra imaginación establece a menudo asociaciones entre los diferentes sentidos, de modo que puede asociarse, por ejemplo, una iluminación abundante con un ambiente cálido, como sucede en la fotografía de la maqueta del museo de arte en Vaduz, de Gigon y Guyer, en la que la luz entra generosamente por la fachada.

Se aprecia, entre los diversos documentos gráficos mostrados, una distinción entre dos tipos. Por una parte, aquellos que pretenden aportar información relativa a decisiones de proyecto - decisiones que afectan a la esencia atmosférica del edificio construido-, pero que no pretenden, como imagen, reproducir dicha esencia atmosférica. En este grupo, que podría denominarse dibujos, se incluirían los bocetos - habitualmente vistas planas, como plantas o secciones- y diagramas, más elaborados y abstractos. Estos requieren una conversión mental para imaginar el espacio tridimensional y la vivencia de dicho espacio. Por otra parte, estarían los que podríamos denominar modelos, y que aspiran a una previsualización figurativa y realística, orientada a despertar sensaciones inmediatas mediante imágenes. Se incluirían aquí las infografías y las fotografías de maquetas.

A la hora de comunicar visualmente la atmósfera, el segundo tipo predomina sobre el primero. Todos los arquitectos buscan de un modo u otro la representación realística: Zumthor, por ejemplo, descarta el uso de infografías, pero sí recurre a la representación realista en sus maquetas. Kerez prefiere las maquetas blancas y estrictamente volumétricas, pero se centra en el render. También Rahm recurre a él en ocasiones, como complemento de sus diagramas. El uso de dibujos permite la evocación de atmósferas, haciendo que el observador complete la imagen bidimensional con una imagen mental tridimensional y multisensorial, pero esto no siempre será posible: si la información es excesivamente abstracta o diagramática, será difícil crear un efecto sensorial en el observador. Independientemente del tipo de documento gráfico elegido, es importante para el arquitecto encontrar el equilibrio entre evocación y definición. Cuanto mayor y más detallada sea la información aportada, menor es el margen dejado a la imaginación, y probablemente menos intensa sea la evocación atmosférica, pues en ella intervienen las emociones y recuerdos. Sin embargo, una imagen excesivamente vaga puede traducirse en una experiencia decepcionante cuando el edificio es construido, por no haber suficiente correspondencia entre dicha imagen y la realidad. En este sentido, el esbozo de Zumthor de la Kunsthaus Bregenz parece funcionar: la planta es identificable en dimensiones y proporciones, pero el nivel de detalle es mínimo, y se centra en lo importante: la entrada de luz. Al mismo tiempo, la experiencia real del vestíbulo, una vez construido el edificio, no se contradice con lo que Zumthor dibujó. En el caso de Sik y el proyecto de viviendas para la tercera edad en Zug, la apuesta ha sido la de la definición más que la evocación, siendo el resultado igualmente positivo por la atención prestada a los detalles en el proyecto, y la fiel correspondencia con la realidad. 


\section{Notas}

1. Su libro "Atmósferas» (Peter Zumthor, Atmosphären. Basilea: Birkhäuser, 2006), publicado a partir de una conferencia pronunciada en 2003 en el castillo de Wendlinghausen (Alemania), es una referencia clave de las bases teóricas del arquitecto y una lectura obligada para entender su obra.

2. En su libro «Naturgeschichte» (Philip Ursprung, Naturgeschichte (Zúrich: Lars Müller, 2005) también hay un capítulo dedicado a la noción de atmósfera, bajo el título «Schönheit und Atmosphäre» [Belleza y atmósfera].

3. Alberto Altés Arlandis, «Partituras e imágenes. Acerca de la insuficiencia de la representación», EGA 16 (2010): 124.

4. Peter Zumthor, Peter Zumthor: Works (Basilea: Birkhäuser, 1999), 7.

5. Jacques Lucan et. al., Matière d'art - Architecture contemporaine en Suisse, (Basilea: Birkhäuser, 2001), 45.

6. Ibídem, 48.

7. Jacques Herzog \& Pierre de Meuron, «One specific room» (1984), visitado el 09/10/13, http://www.herzogdemeuron.com/index/projects/completeworks/026-050/028-lego-house.html.

8. Hans Frei, «Constructing a piece of truth», en Idem., Conflicts (Ostfildern : Hatje Cantz, 2009), 167-169.

9. Sus principios pueden leerse en su manifiesto «Towards a meteorological architecture» (2009), accesible en http://www.philipperahm.com/data/rahmoffice.pdf (visitado el 09/10/13)

\section{Procedencia de las ilustraciones}

Fig. 01. Andrés López Fernández, Arquitectos de la Suiza alemana (Sevilla: Consejería de Obras Públicas y Transportes de la Junta de Andalucía, 1992), 55. Fig. 02. Nobuyuki Yoshida, $A+U$ extra edition: Peter Zumthor (Tokio: A+U Publishing, 1998), 139.

Fig. 03. «Architekturmodelle Peter Zumthor», Detail, visitado el 27-10-2013, http://www.detail.de/architektur/news/architekturmodelle-petezumthor-0 19614.html.

Fig. 04. Jacques Lucan et. al., Matière d'art. Architecture contemporaine en Suisse (Basilea: Birkhäuser, 2001), 48.

Fig. 05. Heinz Wirz, Miroslav Šik. Architecture 1988-2012 (Lucerna: Quart, 2012), 104.

Fig. 06. «Wohnpalazzo fürs Alter», Swiss Architects, visitado el 07-01-2014, http://www.swiss-architects.com/en/projects/42006_Alterswohnungen_Neustadt_2

Fig. 07a. Frank Kaltenbach, «Das Architekturmodell. Werkzeug, Fetisch, kleine Utopie», Detail 7+8 (2012); visitado el 29-10-2013, http: www.detail.de. Fig. 07b. Philip Ursprung, Naturgeschichte (Zúrich: Lars Müller, 2005), 322-323.

Fig. 08. Visitado el 28-10-2013, www.kerez.ch.

Fig. 09. Nobuyuki Yoshida, $A+U$ extra edition: Peter Zumthor, (Tokio: A+U Publishing, 1998), 191.

Fig. 10. Peter Zumthor, Peter Zumthor: Works, (Basilea: Birkhäuser, 1999), 238.

Fig. 11. Christoph Bürkle, Gigon Guyer architects. Works and projects 1989-2000 (Barcelona: Gustavo Gili, 2000), 291.

Fig. 12. Michal Jadczak, «Muzeum nie bêdzie, Kerez pozwany», Art \& Business (2012); visitado el 29-10-2013, http://www.artbiznes.pl/index.php/ muzeum-nie-bedzie-kerez-pozwany/.

Fig. 13. Visitado el 29-10-2013, http://www.philipperahm.com/.

\section{Sobre la autora}

Angélica Fernández estudió arquitectura en la ETSA de Barcelona y la TU Berlín, titulándose en 2003 por la UPC. Ha trabajado como arquitecta en diversos estudios en Barcelona y Zaragoza. Becada por la Fundación La Caixa y el DAAD, en 2006 obtuvo el Master of Arts "Art in Context" por la UdK de Berlín. Desde 2009 es Profesora Ayudante de Expresión Gráfica Arquitectónica en la Universidad de Zaragoza y desarrolla su tesis doctoral en el programa de doctorado "Comunicación Visual en Arquitectura y Diseño" de la UPC, en el marco del cual ha realizado estancias investigadoras en el MACBA de Barcelona y en el archivo GTA de la ETH Zurich. Ha publicado en revistas como EGA y Arquitetura, y participado en congresos nacionales e internacionales. Es miembro del grupo de investigación "Paisajes urbanos y proyecto contemporáneo" de la Universidad de Zaragoza.

angelica.fernandez@unizar.es 